\title{
Peramalan Rate of Return Saham Menggunakan Metode Brown's Weighted Exponential Moving Average dengan Optimasi Levenberg-Marquardt
}

\section{(Forecasting the Stock Rate of Return using the Brown's Weighted Exponential Moving Average Method with Optimization of Levenberg Marquardt)}

\author{
Nur Hasanah Abdullah ${ }^{1^{*}}$, Junaidi, dan Lilies Handayani ${ }^{1}$ \\ 1 Program Studi Statistika, Jurusan Matematika,Fakultas MIPA, UniversitasTadulako, Jl. Soekarno-Hatta Km 9 Tondo, \\ Palu Sulawesi Tengah 94118.
}

Keywords: Weighted Exponential Moving Average, Brown's Double Exponential Smoothing, Brown's Weighted Exponential Moving Average, Optimasi Levenberg-Marquardt, Rate of Return

Keywords: Weighted Exponential Moving Average, Brown's Double Exponential Smoothing, Brown's Weighted Exponential Moving Average, Optimasi Levenberg-Marquardt, Rate of Return

\begin{abstract}
Stocks can be defined as a sign of the participation of unilateral capital in a company or a limited liability company in the form of proof of a company's assets and it is formed as a valueble proof letters as a statement of participating in capital. Return stockis one of the factors that motivates investors to invest or interact and also a reward for the courage of investors to take risks or investments. PT Bank Rakyat Indonesia is one of the largest banks in Indonesia that experiences an increase in stock prices every year. The Brown's Weighted Exponential Moving Average (BWEMA) method which is a combination of the Weighted Exponential Moving Average (WEMA) and Brown's Double Exponential Smoothing (BDES) methods will be used in this study. The data used is the daily data of closing price of the stock (closing price) of PT. Bank Rakyat Indonesia on February 6, 2018 until February 6, 2019. MSE and MAPE BWEMA values were obtained at 6124.222 and $1.831685 \%$, while MSE and MAPE WEMA values were 7559.211 and $1.998439 \%$ respectively. The results obtained show that the BWEMA method has smaller MSE and MAPE values. This shows that the BWEMA method is better than the WEMA method in terms of forecasting. As a results the BWEMA method is continued to calculate the forecasts rate of return for the next 7 days. The average value returns obtained is $0.111497 \%$ stock which means during the period of the investment, investors get a profit of $0.111497 \% \%$ per day of the total funds invested in the shares of PT Bank Rakyat Indonesia (Persero) Tbk.
\end{abstract}

\section{Abstrak}

Saham dapat didefinisikan sebagai tanda penyertaan modal seorang atau sepihak dalam suatu perusahaan atau perseroan terbatas yang berupa suatu bukti atas suatu aset perusahaan yang berbentuk surat tanda bukti berharga sebagai pernyataan ikut memiliki modal. Return saham merupakan salah satu faktor yang memotivasi investor berinvestasi atau berinteraksi dan juga merupakan imbalan atas keberanian investor menanggung risiko atau investasi. PT. Bank Rakyat Indonesia merupakan salah satu Bank terbesar di Indonesia yang mengalami peningkatan. Metode Brown's Weighted Exponential Moving Average (BWEMA) yang merupakan penggabungan dari metode Weighted Exponential Moving Average (WEMA) dan Brown's Double Exponential Smoothing (BDES) akan digunakan dalam penelitian ini. Hasil yang diperoleh menunjukkan metode BWEMA memiliki nilai MSE dan MAPE lebih kecil. Hal ini menunjukkan bahwa metode BWEMA lebih baik dari metode WEMA dalam hal peramalan. Data yang digunakan 
adalah data harian harga penutupan saham (closing price) PT. Bank Rakyat Indonesia pada tanggal 6 Februari 2018 sampai 6 Februari 2019. Diperoleh nilai MSE dan MAPE BWEMA sebesar 6124,222 dan 1,831685\%. Sehingga metode BWEMA dilanjutkan untuk melakukan perhitungan peramalan rate of return saham untuk 7 hari kedepan. Diperoleh nilai rata-rata return saham sebesar $0,111497 \%$ yang artinya selama kurun waktu tahun investasi, investor mendapatkan

* Coresponding Author : hanaabdullah07@gmail.com keuntungan sebesar $0,111497 \% \%$ per hari dari total dana yang diinvestasikan pada saham PT Bank Rakyat Indonesia (Persero) Tbk.

\section{Latar Belakang}

Investasi dalam bentuk saham pada pasar modal di Indonesia mengalami peningkatan ditandai dengan pencapaian jumlah tertinggi perdagangan saham pada Februari 2017 semenjak pasar saham Indonesia didirikan, investor baru pasar modal Indonesia meningkat 23,47\% sepanjang tahun 2016 (Cakti, 2017). Tujuan utama investasi dalam bentuk saham adalah untuk memaksimalkan return dan meminimalkan resiko yang didapatkan dari return (Peng, 2001).

Return saham dapat berupa laba perusahaan yang dibagikan (dividen) atau hasil jual beli saham, namun harga jual dapat berbeda dari harga belinya sehingga ada potensi keuntungan dan kerugian (Zubir, 2013). Investasi pada saham memerlukan analisis yang mendalam agar investor mengetahui kapan harus menjual ataupun membeli saham tertentu sehingga dapat meningkatkan keuntungan, salah satunya dengan meramalkan harga saham yang akan datang. Saham yang memungkinkan dapat dianalisis adalah saham yang diperjualbelikan di pasar modal melalui Bursa Efek Indonesia (BEI) atau Indonesia Stock Exchange (IDX) dikarenakan ketersediaan data harga saham perusahaan-perusahaan yang berstatus terbuka. BEI memberikan data pergerakan harga saham melalui media cetak maupun elektronik. Salah satu media elektronik untuk memperoleh harga saham sendiri dapat dilakukan melalui Yahoo! Finance dalam situs finance.yahoo.com.

PT. Bank Rakyat Indonesia (Persero), Tbk (BRI atau Bank BRI) adalah salah satu bank milik pemerintah terbesar di Indonesia. Sejak 1 Agustus 1992 berdasarkan Undang-Undang Perbankan No. 7 tahun 1992 dan Peraturan Pemerintah RI No. 21 tahun 1992 status BRI berubah menjadi perseroan terbatas. Kepemilikan BRI saat itu masih $100 \%$ di tangan Pemerintah Republik Indonesia. Pada tahun 2003, Pemerintah Indonesia memutuskan untuk menjual 30\% saham bank ini, sehingga menjadi perusahaan publik dengan nama resmi PT. Bank Rakyat Indonesia (Persero) Tbk., yang masih digunakan sampai dengan saat ini. Pemegang saham mayoritas Bank BRI adalah
Pemerintah Republik Indonesia sebesar 56,75\%, sedangkan $43,25 \%$ sisanya dikuasai oleh publik. Harga saham PT. Bank Rakyat Indonesia (Persero), Tbk merupakan salah satu contoh daftar data harga saham yang terbentuk dari waktu ke waktu atau disebut data runtun waktu.

Metode rata-rata bergerak (moving average) merupakan suatu metode sederhana namun sangat penting dalam suatu analisis runtun waktu. Metode rata-rata bergerak tunggal atau dikenal sebagai Simple Moving Average (SMA) merupakan contoh metode rata-rata bergerak paling sederhana yang sering digunakan dalam analisis saham. Metode ini dikatakan rata-rata bergerak karena nilai yang diperoleh dari data baru akan berubah-ubah. Meskipun metode ini cukup baik untuk menentukan trend harga saham di masa mendatang, namun metode ini masih menyimpan kelemahan, yaitu seringkali menghasilkan signal yang terlambat (Suarsa, 2006).

Pada penelitian Hansun (2013), menggabungkan metode Simple Moving Average (SMA), Weighted Moving Average (WMA) dan Exponential Moving Average (EMA) yang disebut sebagai Weighted Exponential Moving Average (WEMA) untuk memprediksi harga saham JKSE composite index. Dalam penelitian tersebut diketahui bahwa metode WEMA menghasilkan nilai error paling kecil atau dapat dikatakan metode terbaik dibandingkan dengan metode moving average lainnya. Pada penelitian selanjutnya (Hansun, 2016), dilakukan kembali pengembangan metode moving average dengan menggabungkan metode WMA dengan Brown's Double Exponential Smoothing (B-DES) dimana dikenal sebagai Brown's Weighted Exponential Moving Average (B-WEMA), kemudian nilai error pada BWEMA dibandingkan dengan metode WMA dan BDES. Kesimpulan yang didapat, B-WEMA memberikan nilai error lebih kecil yang artinya metode B-WEMA lebih baik dibandingkan dengan metode lainnya. Penelitian selanjutnya (Primandari, 2016) dengan judul "Grey Double Exponential Smoothing dengan Optimasi Levenberg-Marquardt untuk Peramalan Volume Penumpang di Bandara Soekarno-Hatto" kemudian 
hasilnya setelah parameter alpha dioptimasi menggunakan algoritma Levenberg-Marquardt baik dalam G-DES maupun DES. Dalam kasus ini penggunaan metode grey cukup efektif dibandingkan dengan tanpa metode grey.

Berdasarkan uraian diatas, pada penelitian ini dilakukan penerapan metode Brown's Weighted Exponential Moving Average pada harga saham PT. Bank Rakyat Indonesia (Persero), Tbk dengan optimasi parameter Levenberg-Marquardt (LM), dimana package dalam $\mathrm{R}$ yang digunakan untuk optimasi adalah library (minpack.Im). Pada library (minpack.Im) terdapat beberapa function untuk melakukan optimasi, salah satu function yang ada adalah "nls.Im" dimana function ini melakukan optimasi menggunakan metode Levenberg-Marquardt (LM). (Elzhov dkk, 2016).

\section{Bahan dan Metode}

Data yang digunakan dalam penelitian ini merupakan data sekunder yang diperoleh dari situs finance.yahoo.com yaitu data harga saham penutupan (closing price) PT. Bank Rakyat Indonesia (Persero), Tbk. yang terdiri dari data harian selama satu tahun perdagangan (262 hari bisnis) terhitung mulai 6 Februari 2018 sampai dengan 6 Februari 2019.

Metode yang digunakan pada penelitian ini adalah Brown's Weighted Exponential Moving Average. Tahapan analisis yang digunakan pada penelitian ini adalah sebagai berikut :

1. Membuat fungsi peramalan WEMA.

2. Menentukan nilai parameter alpha $2 /(k+1)$ pada WEMA.

3. Melakukan perhitungan MSE dan MAPE pada WEMA.

4. Membuat fungsi peramalan BWEMA.

5. Melakukan optimasi parameter alpha metode Levenberg Marquadrt pada BWEMA.

6. Melakukan perhitungan MSE dan MAPE pada BWEMA.

7. Memilih model terbaik antara metode WEMA dengan BWEMA berdasarkan MSE dan MAPE.

8. Peramalan rate of returrn saham dengan metode terbaik.

9. Interpretasi dan Kesimpulan.

\section{Hasil dan Pembahasan}

Berikut merupakan proses analisis Peramalan Rate Of Return Saham Menggunakan Metode Brown's Weighted Exponential Moving Average Dengan Optimasi Levenberg-Marquardt.
Brown's Weighted Exponential Moving Average (BWEMA)

Peramalan harga penutupan saham PT. Bank Rakyat Indonesia akan dilakukan dengan metode Brown's Weighted Exponential Moving Average (B-WEMA) dengan optimasi parameter Levenberg-Marquardt (LM). Package minpack.Im pada program $R$ digunakan sebagai alat bantu yang kemudian dibandingkan dengan Weighted Exponential Moving Average (WEMA) dimana metode terbaik dilihat dari metode yang memiliki nilai Mean Square Error (MSE) dan Mean Average Percentage Error (MAPE) terkecil yang digunakan untuk memprediksi rate of return saham PT Bank BRI (Persero) Tbk.

Optimasi LM hanya dilakukan untuk metode yang merupakan model dari exponential smoothing karena pada hal ini yang dioptimalkan adalah parameter pemulusan alpha exponential smoothing sehingga diharapkan model exponential smoothing memiliki MSE ataupun MAPE terkecil dimana algoritma LM tersebut memperkecil fungsi chi-square. Parameter alpha awal yang digunakan yaitu sebesar 0,3333 dengan $k=5$, kemudian setelah di optimasi menggunakan Levenberg Marquardt diperoleh parameter alpha optimum sebesar 0,5098, dapat dilihat hasilnya pada Lampiran 6. Pada metode WEMA tidak dilakukan proses pengoptimalan parameter alpha karena metode WEMA tidak termasuk ke dalam metode exponential smoothing sehingga parameter yang digunakan pada WEMA sudah merupakan nilai parameter maksimum, yaitu sebesar 0,3333 .

\section{Perbandingan Nilai Error (MSE dan MAPE)}

Untuk hasil terbaik, dilihat berdasarkan nilai error terkecil dari MSE dan MAPE pada masing-masing metode. Berdasarkan Tabel 1 metode BWEMA memperoleh nilai MSE sebesar 6124,222 serta MAPE terkecil yaitu MSE sebesar 1,831685\% dibandingkan metode WEMA. Metode WEMA memiliki nilai MSE sebesar 7559,211 dan MAPE sebesar 1,998439\%. Sehingga dapat dikatakan bahwa metode BWEMA lebih baik daripada metode WEMA.

Tabel 1. Nilai Error MSE dan MAPE

\begin{tabular}{ccc}
\hline Metode & MSE & MAPE \\
\hline WEMA & 7559,211 & $1,998439 \%$ \\
BWEMA & 6124,222 & $1,831685 \%$
\end{tabular}




\section{Perbandingan Hasil Peramalan Metode WEMA dengan BWEMA}

Berdasarkan Gambar 1 dapat dilihat plot hasil peramalan data harga penutupan saham PT Bank Rakyat Indonesia terhitung pada tanggal 6 Februari 2018 sampai dengan 6 Februari 2019 dengan menggunakan metode Weighted Exponential Moving Average (WEMA). Dari plot tersebut untuk data aktual ditandai dengan warna biru, sedangkan hasil peramalan WEMA ditandai dengan warna merah, untuk sumbu $x$ nya menunjukkan hari sedangkan sumbu $y$ nya menunjukkan data harga saham.



Hari

Gambar 1. Plot Weighted Exponential Moving Average

Plot hasil peramalan metode WEMA tidak terlalu mengikuti data aktual hal ini dapat dilihat dari plot diatas, akan tetapi di akhir periode metode WEMA juga mengalami kenaikan harga saham pada data ke 196 sampai 261. Meskipun tidak begitu mengikuti data aktual namun metode WEMA dengan data aktual tidak begitu jauh berbeda pola data harga sahamnya.

Berdasarkan Gambar 2 dapat dilihat plot hasil peramalan data harga penutupan saham PT Bank Rakyat Indonesia terhitung pada tanggal 6 Februari 2018 sampai dengan 6 Februari 2019 dengan menggunakan metode Brown's Weighted Exponential Moving Average (BWEMA). Dari plot tersebut untuk data aktual ditandai dengan warna biru, sedangkan hasil peramalan BWEMA ditandai dengan warna merah, untuk sumbu $x$ nya menunjukkan hari sedangkan sumbu y nya menunjukkan data harga saham. Berdasarkan Gambar 2 hasil peramalan metode BWEMA mengikuti data aktual hal ini dapat dilihat dari plot diatas, dapat dilihat juga di akhir periode metode BWEMA juga mengalami kenaikan harga saham pada data ke 197 sampai 253.
Dari kedua plot WEMA dan BWEMA di atas berdasarkan data aktual closing price saham Bank BRI metode BWEMA lebih mengikuti data aktual dibanding metode WEMA. Hasil analisa yang diperoleh peramalan BWEMA dan WEMA dapat disimpulkan bahwa peramalan harga penutupan saham menggunakan BWEMA lebih baik daripada WEMA.

\section{Rate of Return Saham}

Perhitungan nilai rate of return saham atau tingkat pengembalian dari saham Bank BRI dilakukan menggunakan rumus sebagai berikut.

$$
R=\log \left(\frac{P_{t}}{P_{t-1}}\right)
$$

Berikut merupakan contoh perhitungan return saham, diketahui bahwa dengan $\mathrm{Rp} 3.700,00$ merupakan data closing price saham pada saat return pertama yaitu pada tanggal 7 Februari 2018, dan Rp $3.680,00$ merupakan data closing price saham pada saat tidak terbentuknya return pada tanggal 6 Februari 2018.

$$
\begin{aligned}
R & =\log \left(\frac{P_{t}}{P_{t-1}}\right) \\
& =\log \left(\frac{3700}{3680}\right) \\
& =0,002353905
\end{aligned}
$$

Untuk mengubah nilai return menjadi rate of return dengan dikalikan 100 (dalam \%) maka nilai rate of return pertama yaitu sebesar $0,2353905 \%$ atau dapat dikatakan investor mendapatkan keuntungan 0,2353905\% dari total dana yang diinvestasikan pada saham Bank BRI dalam satu hari.

Tabel 2. Forecast BWEMA Untuk Prediksi Rate of Return Saham

\begin{tabular}{ccc}
\hline Date & Close & Rate of Return \\
\hline $06 / 02 / 2018$ & 3680 & - \\
$07 / 02 / 2018$ & 3700 & $0,2353905 \%$ \\
$08 / 02 / 2018$ & 3720 & $0,2341216 \%$ \\
$09 / 02 / 2018$ & 3710 & $-0,116903$ \\
$12 / 02 / 2018$ & 3800 & 1,0409687 \\
$13 / 02 / 2018$ & 3880 & 0,9048129 \\
$14 / 02 / 2018$ & 3860 & $-0,2244421$ \\
$\vdots$ & $\vdots$ & $\vdots$ \\
$07 / 02 / 2019$ & 3920,276198 & $0,00305987 \%$ \\
$08 / 02 / 2019$ & 3923,91566 & $0,0402998 \%$ \\
$09 / 02 / 2019$ & 3927,555121 & $0,0402625 \%$ \\
$10 / 02 / 2019$ & 3931,194582 & $0,0402252 \%$ \\
$11 / 02 / 2019$ & 3934,834043 & $0,040188 \%$ \\
$12 / 02 / 2019$ & 3938,473505 & $0,0401508 \%$ \\
$13 / 02 / 2019$ & 3942,112966 & $0,0401137 \%$ \\
& & $\bar{x}=0,111497 \%$ \\
\hline
\end{tabular}


Pada perbandingan hasil berdasarkan nilai error yang terkecil atau terbaik pada nilai MSE dan MAPE diketahui bahwa metode BWEMA lebih baik dibandingkan metode WEMA. Maka metode hasil dari peramalan menggunakan metode BWEMA dilanjutkan untuk melakukan analisis prediksi rate of return saham Bank BRI. Peramalan satu hari ke depan untuk BWEMA telah dilakukan menggunakan software $R$, kemudian peramalan berikutnya dilanjutkan menggunakan Microsoft Excel dimana $m=2$ untuk peramalan hari kedua, dan $m=3$ untuk peramalan hari ketiga dan seterusnya. Nilai hasil peramalan 7 hari ke depan dengan B-WEMA ini digunakan untuk mendapatkan nilai rate of return saham 7 hari ke depan yang hasilnya seperti pada Tabel 2 .

Hasil peramalan harga penutupan saham PT. Bank BRI seperti pada tampak tabel diatas diperoleh hasil peramalan harga saham Bank BRI selama 7 hari ke depan, dan rata-rata nilai rate of return saham sebesar $0,111497 \%$ yang berarti selama kurun waktu tahun investasi, investor mendapatkan keuntungan sebesar $0,111497 \%$ per hari dari total dana yang diinvestasikan pada saham PT Bank BRI (Persero) Tbk.

Berdasarkan grafik pada Gambar 3 diperoleh rate of return saham dari hasil peramalan menggunakan metode terbaik yaitu metode Brown's Weighted
Exponential Moving Average. Average (rata-rata) rate of return ditandai dengan warna kuning sedangkan nilai rate of return nya ditandai dengan warna biru, dapat disimpulkan bahwa pergerakan plot return harga closing price saham PT. Bank Rakyat Indonesia cenderung stabil. Grafik menunjukkan bahwa return yang diperoleh sangat bervariasi. Nilai return saham PT. Bank Rakyat Indonesia mempunyai nilai rata-rata positif yaitu sebesar 0,111497\% yang menunjukkan bahwa selama periode tersebut harga saham mengalami kenaikan.

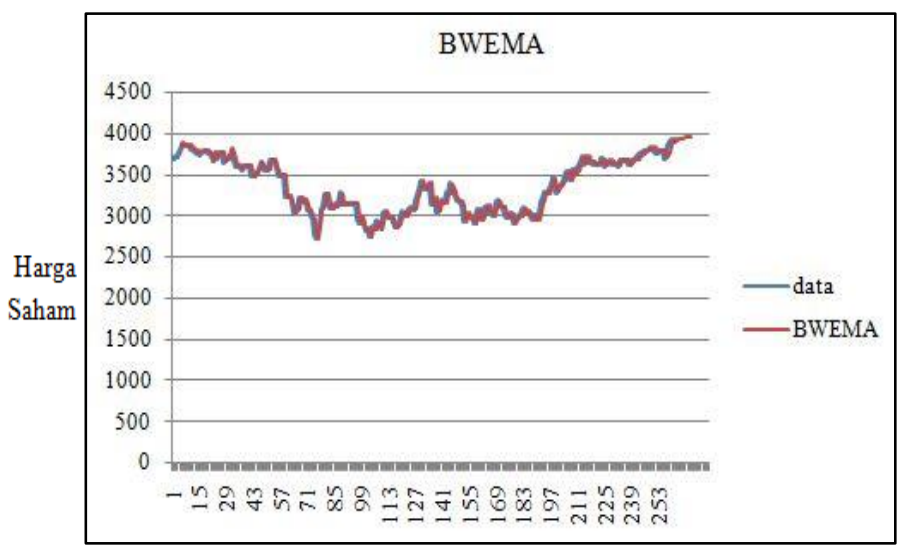

Hari

Gambar 2. Plot Brown's Weighted Exponential Moving Average

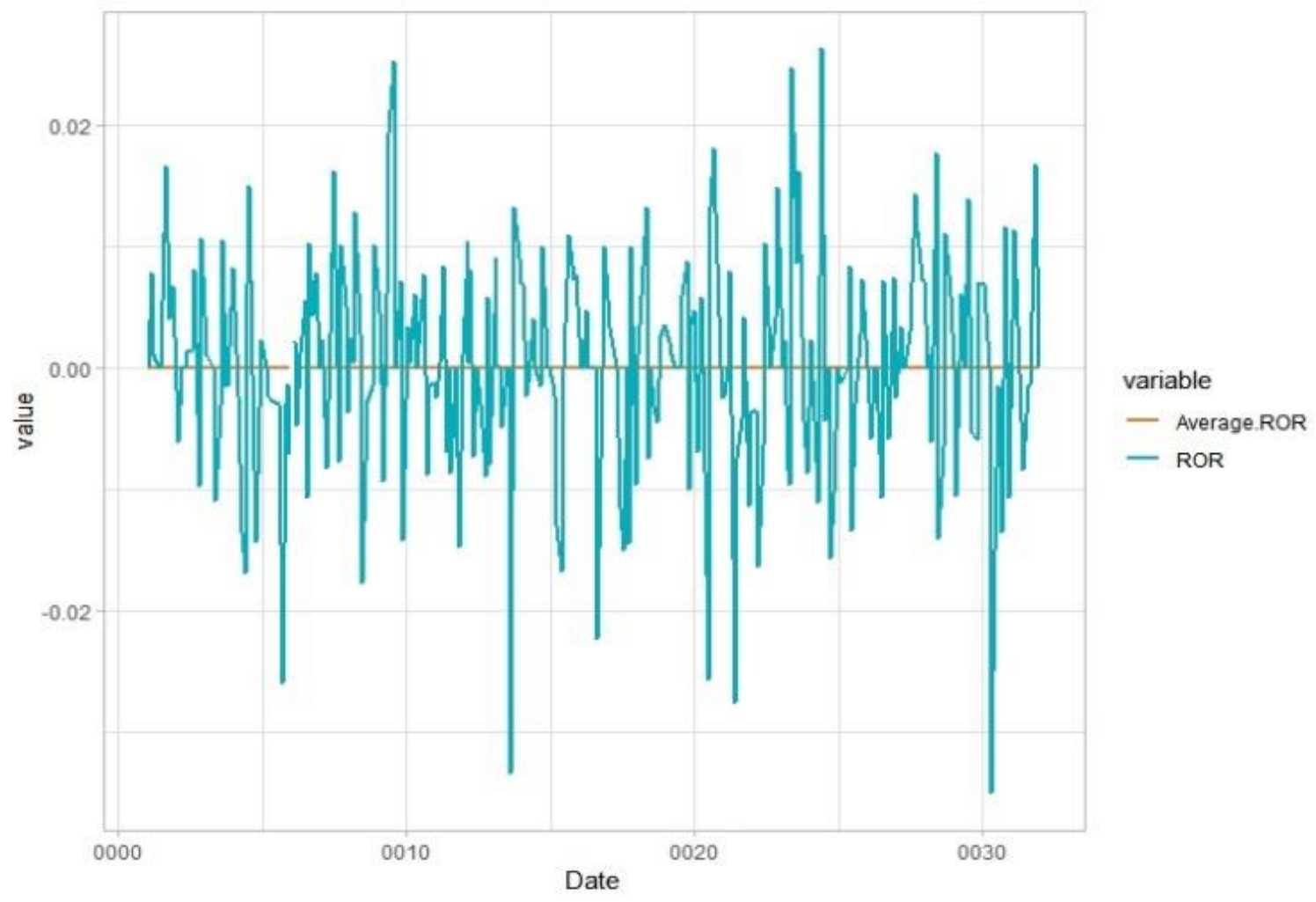

Gambar 3. Plot Rate of Return Saham 


\section{UCAPAN TERIMAKASIH}

Penulis mengucapkan terima kasih kepada PT. Bank Rakyat Indonesia yang telah memperkenankan penulis untuk mengambil data harga penutupan saham.

\section{DAFTAR PUSTAKA}

Cakti, G. A. (2017, February 17). Market Bisnis Indonesia. Diambil kembali dari MarketBisnis: http://market.bisnis.com/read/20170217/7/62966 0/sepanjang-2016-jumlah-investor-baru-di-pasarmodal-indonesia-naik-23.47. Diunduh Tanggal 20 Desember 2018, Pukul 20.00 WIB.

Elzhov, T.V., Mullen K.M., Spiess, A.N., \& Bolker, B. (2016, November 20). Cran.R. Diambil kembali dari Cran.R Project: https://cran.rproject.org/web/packages/minpack.Im/minpack.I m.pdf.

Hansun. (2013). A New Approach of Moving Average Method in Time Series Analysis. International Conference on New Media (CoNMedia) (hal. 14). Indonesia: Proc. of the 2013 IEEE
International Conference on New Media.

Hansun. (2016). A New Approach of Brown's Double Exponential Smoothing Method in Time Series Analysis. Balkan Journal of Electrical \& Computer Engineering (BAJECE), 75-78.

Peng, C. S. (2001). Profit from Online Stock Investment. Singapura: Mc-Graw-Hill Education.

Primandari, A. H. (2016). Grey Double Exponential Smoothing dengan Optimasi LevenbergMarquardt untuk Peramalan Volume Penumpang di Bandara Soekarno-Hatta. Jurnal Derivt 3(2): 25-39.

Suarsa, (2006). Perbandingan Analisa Teknikal Metode Simple Moving Average, Weigted Moving Average, dan Exponential Moving Average Dalam Memprediksi Harga Saham LQ-45 Sub Sektor Telekomunikasi di Bursa Efek Jakarta. Bandung: Sekolah Tinggi IImu Eknonomi Muhammadiyah Bandung.

Zubir, Z. (2013). Manajemen Portofolio Penerapannya dalam Investasi Saham. Jakarta: Salemba Empat. 